\title{
A prática do psicólogo hospitalar em equipe multidisciplinar
}

\section{The practice of hospital psychologist in a multidisciplinary team}

\author{
Aline Maria TONETTO2 \\ William Barbosa GOMES ${ }^{3}$
}

\begin{abstract}
Resumo
Este trabalho analisa a interação estabelecida no hospital entre a Psicologia e a Enfermagem para identificar aspectos capazes de promover a ação multidisciplinar. Foram entrevistadas sete psicólogas hospitalares, três enfermeiras, e observadas várias situações de intervenção psicológica. Os conteúdos obtidos foram analisados qualitativamente através de três etapas sinérgicas: descrição, análise indutiva e análise crítica. A descrição e a análise indutiva trazem a questão do poder hierárquico e da visão reducionista do médico como obstáculo à prática multidisciplinar. A Enfermagem reconhece a importância da intervenção psicológica, mas avalia que o psicólogo nem sempre consegue justificar a pertinência de um atendimento à equipe. A análise crítica destacou que a prática multidisciplinar depende de o psicólogo deslocar o foco da doença em si para uma visão mais integrada do processo saúde-doença, o que implica ser capaz de justificar procedimentos psicológicos de forma clara e objetiva.
\end{abstract}

Unitermos: enfermagem; hospitais; intervenção psicológica.

\begin{abstract}
The interaction between hospital psychologists and nursing professionals is examined in order to identify the multidisciplinary activity aspects. Seven hospital psychologists and three nurses were interviewed. Also, the psychologists' activities carried out in different hospital settings were observed. The results were analyzed qualitatively through three synergic steps: description, inductive analysis and critical analysis. The description and the inductive analysis brought up the hierarchical power and doctors'reduced vision as obstacles to the multidisciplinary practice. While nursing acknowledges the importance of the psychological intervention, they consider psychologists rarely justify its importance to the team. The critical analysis showed that the multidisciplinary practice depends on the psychologist to displace the focus from the illness towards a more integrated vision of the health-illness process. Such a displacement involves the competency tojustify psychological procedures in a clear and objective way.
\end{abstract}

Uniterms: nurses; hospitals; psychological intervention.

O trabalho em equipe é hoje uma prática crescente no atendimento à saúde (Bucher, 2003; Maclean, Plotnikoff \& Moyer, 2000; Moré, Crepaldi, Queiroz, Wendt \& Cardoso, 2004; Remor, 1999; Seidl \& Costa, 1999; Wild, Bowden \& Bell, 2003). As equipes se caracterizam pelo modo de interação presente na relação entre profissionais (Chiattone, 2000; Maclean et al., 2000), que pode ser interdisciplinar, multidisciplinar e transdisciplinar.

A interação é interdisciplinar quando alguns especialistas discutem entre si a situação de um paciente

$\boldsymbol{\nabla} \boldsymbol{\nabla} \boldsymbol{\nabla}$

1 A pesquisa contou com apoio da Coordenação de Aperfeiçoamento de Pessoal de Nível Superior e do Conselho Nacional do Desenvolvimento Científico e Tecnológico (Proc. no 471273/2003-1)

2 Mestre em Psicologia, Universidade Federal do Rio Grande do Sul, Programa de Pós-Graduação em Psicologia. Porto Alegre, RS, Brasil.

3 Universidade Federal do Rio Grande do Sul, Instituto de Psicologia. Rua Ramiro Barcelos, 2600, 90035-003, Porto Alegre, RS, Brasil. Correspondência para/Correspondence to: W.B. GOMES. E-mail: <gomesw@ufrgs.br>. 
sobre aspectos comuns a mais de uma especialidade. É multidisciplinar quando existem vários profissionais atendendo o mesmo paciente de maneira independente. É transdisciplinar quando as ações são definidas e planejadas em conjunto. Na prática, poucos são os trabalhos que contemplam essa diferenciação. Independente do termo empregado, há expectativas de que profissionais da saúde sejam capazes de ultrapassar o desempenho técnico baseado em uma única arte ou especialização (Bucher, 2003; LoBianco, Bastos, Nunes \& Silva, 1994).

Reconheça-se, contudo, que o interesse pelo trabalho em equipe multidisciplinar vem se fortalecendo, tendo como base a crescente aceitação do modelo biopsicossocial de saúde. Nesse modelo, saúde é definida como o bem-estar físico, mental e social, em contraste com o modelo biomédico tradicional para o qual saúde é a ausência de doença (Organização Panamericana da Saúde, 1996).

A organização ou mobilização de equipes está associada à complexidade da demanda (Crepaldi, 1999). Nessas situações, os profissionais se deparam com seus próprios limites e encontram nos colegas de outras formações subsídios para a compreensão e atendimento do caso em questão. No entanto, tal atitude não é uma conduta padrão, podendo variar conforme a tradição profissional, a característica do grupo de trabalho e o tipo de intervenção (Chiattone, 2000). Na verdade, o trabalho em equipe traz novos desafios, exigindo competências e habilidades para o trabalho em grupo e para a justificação clara e objetiva de procedimentos técnicos pertencentes à dada especialidade.

No âmbito hospitalar, a falta de clareza quanto às atribuições dos diferentes profissionais, principalmente em profissões emergentes, é um dos fatores que dificulta o trabalho em equipe. O hospital é uma instituição complexa, que envolve um grande número de especialidades. Esses profissionais são preparados para tomar decisões importantes em curto espaço de tempo. Tradicionalmente, tais decisões competem aos médicos. No entanto, com o aparecimento de novas especialidades, os médicos contam hoje com o auxílio de diversos profissionais de campos emergentes. Um desses campos é a Psicologia.

A crescente inserção da Psicologia em equipes 90 de saúde é hoje um fato reconhecido (LoBianco et al.,
1994). No âmbito hospitalar, sabe-se que a Psicologia vem participando mais ativamente na definição de condutas e tratamentos (Romano, 1999). Contudo, há queixas entre psicólogos de que muitas das suas observações clínicas não são prontamente aceitas pelas equipes. Tais dificuldades têm gerado discussões sobre qual o modo mais apropriado da Psicologia se inserir nas equipes multidisciplinares.

Uma primeira condição para o trabalho multidisciplinar efetivo do psicólogo é a clareza de suas atribuições e das expectativas concernentes a sua especificidade (Romano, 1999). No caso de estarem esclarecidas as atribuições do psicólogo, espera-se que ele seja capaz de se mostrar competente o suficiente para que sua prática seja vista como necessária (Chiattone, 2000; Moré et al., 2004).

Uma das dificuldades apontadas na relação do psicólogo com a equipe é a ausência de linguagem clara e objetiva. Em contraste, Seidl e Costa (1999) informaram que tais dificuldades diminuem quando o psicólogo é pós-graduado, desenvolve atividades de pesquisa e participa de eventos científicos.

Em estudo realizado na Escócia, Wild et al. (2003) verificaram que o baixo índice de encaminhamento para tratamento psicológico estava mais relacionado à falta de compreensão da prática do que à desconfiança dos métodos. A partir desses resultados, os autores concluíram que há necessidade dos psicólogos hospitalares investirem em canais de comunicação que permitam divulgar e esclarecer o trabalho que realizam ou podem realizar em hospitais.

Apesar dos avanços obtidos, o trabalho em equipe ainda constitui um importante desafio para o desenvolvimento da Psicologia Hospitalar (Seidl \& Costa, 1999; Yamamoto \& Cunha, 1998). Gavião e Pinto (2000) ouviram 80 psicólogos que trabalhavam em hospital e concluíram que o compromisso interprofissional é ainda muito idealizado. Com efeito, a intervenção multidisciplinar não ocorre de modo freqüente e sistemático (Bucher, 2003; Crepaldi, 1999), podendo ser prejudicada por uma rígida discriminação hierárquica (Romano, 1999). A discriminação hierárquica ocorre quando não se diferencia status de função, substituindo-se as especificidades de cada membro da equipe pelas relações de poder. A dinâmica de trabalho em equipe, fundamentada na diferença de cada especialista, depen- 
de da autonomia e do compartilhamento de responsabilidades. Em uma equipe bem-sucedida, o diálogo é aberto e cooperativo, favorecendo o rodízio natural de lideranças situacionais (Romano, 1999).

Este estudo é uma proposta de inserção na prática da Psicologia em hospitais através de dois olhares: a reflexão da Psicologia sobre a própria prática em equipes multidisciplinares e a observação da Enfermagem sobre a participação da Psicologia nessas interações. Epistemologicamente, o estudo estabelece uma conversa entre a primeira pessoa do psicólogo (como eu faço e como eu sinto) com a terceira pessoa do enfermeiro (como ele faz e eu vejo).

Espera-se que esta pesquisa revele aspectos da rotina psicológica em hospitais e aponte exemplos de inserções bem-sucedidas e aspectos que requerem maior atenção e pesquisa.

\section{Método}

\section{Participantes}

Participaram deste estudo sete psicólogas (Tabela 1) e três enfermeiras (Tabela 2), procedentes de quatro instituições da cidade de Porto Alegre, RS: A) particular (hospital confessional com atendimento a particulares e a convênios); B) público-escola (hospital vinculado à universidade pública); C) público (hospital gerenciado pelo Sistema Único de Saúde - SUS), e D) misto-escola (hospital confessional com atendimento a particulares, a convênios e ao SUS).

As psicólogas foram selecionadas a partir do núcleo de psicólogos hospitalares de cada instituição. Nos locais com mais de dois psicólogos envolvidos com atendimento de pacientes, familiares e equipe, foram solicitadas a participarem do estudo aquelas com mais tempo na instituição. Uma instituição consultada não indicou um profissional da Psicologia, inviabilizando a inclusão na pesquisa. Todos os hospitais consultados ofereciam estágio de Psicologia para cursos de graduação, embora nem todas as psicólogas participantes fossem supervisoras de estágio. Quanto às enfermeiras, uma foi indicada por trabalhar com psicólogos em equipe multidiscipinar há vários anos. As demais foram indicadas pelas psicólogas participantes. No hospital público as psicólogas informaram não haver enfermeiras dispostas a colaborar com a pesquisa.

\section{Instrumentos}

O contato com as profissionais se deu por meio de entrevistas e observações. Antes da entrevista, as psicólogas foram observadas em situações de atendimento psicológico. As observações incluíam a

Tabela 1. Perfil das psicólogas entrevistadas.

\begin{tabular}{|c|c|c|c|c|c|}
\hline Psicóloga & Idade (anos) & Tempo de serviço (anos) & Carga horária hospitalar & Natureza do hospital & Outra atividade \\
\hline $\mathrm{A} 1$ & 37 & 6 & $40 \mathrm{~h} /$ semanais & Particular & Clínica \\
\hline$A 2$ & 33 & 4 & $40 \mathrm{~h} /$ semanais & Particular & Clínica \\
\hline B1 & 29 & 5 & $30 \mathrm{~h} / \mathrm{semanais}$ & Público/escola & Consultório \\
\hline B2 & 37 & 12 & $30 \mathrm{~h} /$ semanais & Público/escola & Consultório \\
\hline $\mathrm{C} 1$ & 45 & 19 & $30 \mathrm{~h} /$ semanais & Público & - \\
\hline $\mathrm{C}_{2}$ & 45 & 16 & $30 \mathrm{~h} /$ semanais & Público & Consultório \\
\hline D1 & 23 & $4^{*}$ & $20 \mathrm{~h} /$ semanais & Misto/escola & Consultório \\
\hline
\end{tabular}

* Seis meses como psicóloga e três anos e meio como estagiária

Tabela 2. Perfil das enfermeiras entrevistadas.

\begin{tabular}{lccccc}
\hline Psicóloga & Idade (anos) & Tempo de atuação (anos) & Unidade de atuação & Natureza do hospital & Função \\
\hline A3 & 32 & 13 & Maternidade & Particular \\
B3 & 47 & 25 & UTI Neonatal & Público/escola & Enfermeira \\
D3 & 48 & 26 & Pediatria & Misto & Enfermeira \\
\hline
\end{tabular}


descrição do local de atendimento e as verbalizações da profissional. Em algumas das situações observadas, as atividades foram executadas por estagiários que estavam sob supervisão da psicóloga participante. As entrevistas orientaram-se por roteiros tópicos flexíveis elaborados especialmente para este estudo. A entrevista com as psicólogas focalizou as experiências, opiniões, conhecimentos e sentimentos dessas profissionais sobre o trabalho em hospitais. Como perguntas típicas da entrevista podem-se mencionar: Que tipo de atividades tem realizado na instituição em que trabalha? Qual a demanda e quais os objetivos do trabalho realizado? Quais as atividades que considera peculiar do trabalho em Psicologia Hospitalar? Qual a relação das atividades que desenvolve com os demais serviços oferecidos pela instituição em que trabalha? Se for o caso, que estratégias são utilizadas para integrar-se aos demais profissionais? Quais os maiores desafios enfrentados na prática da Psicologia Hospitalar? Como percebe a valorização do que faz pelos demais profissionais da instituição?

A entrevista das enfermeiras abordou as experiências, opiniões, conhecimentos e sentimentos das profissionais em relação ao trabalho das psicólogas. As perguntas da entrevista foram: Qual a sua formação profissional? Há quanto tempo você trabalha na instituição? E no setor que atualmente desenvolve suas atividades? Você costuma exercer sua profissão a partir do trabalho em equipe? A sua formação foi orientada para o trabalho em equipe? Como você avalia a implementação do trabalho em equipe na área da saúde? Quais os profissionais que você considera importantes para compor as equipes na área da saúde? Qual a sua experiência de trabalho com psicólogos? Como foi ou está sendo? O que você concebe como sendo função do psicólogo nos trabalhos em equipe? Que aspectos você destacaria do trabalho dos psicólogos que você trabalhou? A quais aspectos você acredita que os psicólogos deveriam dar mais atenção? Como você avalia a inserção dos psicólogos nas equipes de saúde?

\section{Procedimentos}

As observações e as entrevistas foram agendadas 92 conforme consentimento e disponibilidade dos participantes. As observações foram autorizadas apenas em dois hospitais: no público/escola e no misto/escola. Todas as observações foram registradas em diário de campo para posterior análise. O tempo médio de duração de cada atividade observada foi de 60 minutos. Em ambos os hospitais, o local de realização das atividades observadas variou conforme seu objetivo e público-alvo. A pesquisadora (primeira autora) encontrava com as psicólogas ou estagiárias, responsáveis pelo desenvolvimento das atividades observadas, na sala do serviço de Psicologia, momentos antes do início de cada atividade.

No hospital público/escola puderam ser acompanhadas somente as atividades realizadas ou supervisionadas pelas psicólogas participantes que não sofressem interferências com a presença do pesquisador. Foram observadas as seguintes atividades consideradas multidisciplinares: grupo de pais da UTI neonatal; grupo de portadores de osteoartrose; grupo de gestantes; grupo de mulheres portadoras do vírus HIV.

No hospital misto/escola foi possível acompanhar as diversas atividades multidisciplinares realizadas pela Psicologia: grupo de pais da UTI infantil; grupo de pacientes do SUS; grupo de pais de pacientes de convênios e particulares; reunião da equipe de cirurgia torácica e reunião do comitê gestor do hospital.

As psicólogas dos hospitais público e particular não permitiram que fossem realizadas as observações porque as atividades consistiam basicamente em atendimentos individuais. As profissionais do hospital particular alegaram ainda que a presença do pesquisador nas atividades realizadas em grupos poderia constranger os participantes e, portanto, prejudicar o desenvolvimento dos trabalhos.

As entrevistas com as psicólogas e as enfermeiras foram realizadas nos hospitais, depois de concluídas as observações. O relato das entrevistadas foi gravado em áudio e transcrito na íntegra. O tempo médio de duração das entrevistas com as psicólogas foi de 70 minutos, e com as enfermeiras de 40 minutos. Todas as participantes assinaram o Termo de Consentimento Livre e Esclarecido.

\section{Critérios de análise}

O conteúdo das observações e das entrevistas foi analisado qualitativamente em três etapas siste- 
máticas e sinérgicas, conhecidas como descrição, análise indutiva e análise crítica (Gomes, 1998). Na descrição procura-se relatar o fenômeno estudado conforme vivenciado pelos participantes, de modo direto e não avaliativo. Na análise indutiva escolhem-se partes da descrição que se mostrem essenciais ao esclarecimento da questão que se quer compreender. A escolha entre partes segue a técnica da variação imaginativa livre, processo de sucessivos questionamentos sobre as presenças e ausências que compõem o relato da descrição (Lanigan, 1988). Nessa fase, o pesquisador revê sua compreensão inicial do problema, demarcando aquelas experiências consideradas essenciais.

Na análise crítica os pesquisadores propõem uma compreensão possível ao fenômeno estudado, tendo em vista propostas de mudanças ou de apropriação dos aspectos positivos encontrados. As recorrências (repetições de certo tema ou observação em várias entrevistas) serão tratadas qualitativamente como possibilidades potenciais e não como quantidades reais.

As etapas de análise deste estudo são informadas a seguir. Inicialmente preparou-se uma exaustiva descrição compreensiva do que havia sido documentado em observações e entrevistas (1 a etapa). Procedeu-se então à análise indutiva com a definição dos temas tratados na entrevista, seja por associação às perguntas, seja por introdução espontânea das entrevistadas. Cada tema foi documentado por excertos retirados das observações e das entrevistas ( $2^{a}$ etapa). O resultado dessa operação foi, portanto, a primeira interpretação qualitativa do estudo (3a etapa).

A primeira interpretação qualitativa foi tomada, então, como descrição, no caso documentado por excertos previamente selecionados ( 1 a etapa) para servir de base aos questionamentos da análise indutiva (2a etapa). A análise crítica abarcou o conjunto das análises indutivas, dialogando com o contexto geral das entrevistas e com a literatura (3a etapa). Para maiores informações sobre essa modalidade de análise qualitativa ver Oliveira e Gomes (2004) e Souza, Gomes e McCarthy (2005).

\section{Resultados}

A apresentação dos resultados está organizada em duas partes. A primeira focaliza a perspectiva das psicólogas e a segunda a das enfermeiras.

\section{Primeira parte: prática multidisciplinar na perspectiva das psicólogas}

As psicólogas consideram que o modo de interação que estabelecem com os demais profissionais em um hospital depende de questões hierárquicas; do grau de importância atribuída aos aspectos emocionais; e do conhecimento existente sobre o trabalho da Psicologia. Sendo assim, as condições de trabalho variam de hospital para hospital, e em um mesmo hospital entre as diversas unidades. Por sua vez, o atendimento pode variar da ação isolada em uma unidade à ação integrada em outra.

Os depoimentos obtidos foram agrupados em dois temas: 1) inserção em equipes e 2) prática multidisciplinar. As etapas reflexivas serão abertas com uma pergunta para orientação do foco a ser considerado. Cada pergunta procurará estabelecer uma relação entre o olhar do pesquisador e as falas obtidas nas entrevistas.

\section{Descrição do primeiro tema: a inserção da Psicologia em equipes multidisciplinares}

Quais são as questões de hierarquia, de importância emocional, e de conhecimento sobre a Psicologia na percepção das psicólogas, no contexto das equipes multidisciplinares?

- A questão da hierarquia:

O hospital é a casa do médico e a psicóloga está aqui pagando aluguel, no sentido assim de estar aqui pra contribuir, pra ajudar porque os médicos sabem que não dão conta sozinhos. Mas quem realmenteé importante na história são eles, isso éalgo bem visível (B1).

Como lidar com isso assim, no sentido de não desvalorizar nosso trabalho e também de não interferir na questão do médico? (A2).

Há [médicos] que querem, que fazem questão, que nos procuram. Mas há outros que surpreendem de chegar [e dizer] olha eu não quero: o que tu podes fazer pelo meu paciente se ele está morrendo? Talvez pelo paciente, indiretamente, mas pela família muito né? Tem muito de desinformação (A2).

Eu tenho um médico aqui que diz assim, mas vocês estão semprefalando o óbvio, a gente sabe que o paciente que recebe psicólogo é tudo de bom. Mas me prova que é tudo de bom. E tu ficas numa reunião lá da diretoria assim, tu achando que tu tá fazendo um baita dum 
projeto e aí eles chegam eu quero números, me mostra, e aía gente fica olhando pra eles (A1).

A Psicologia questionou se há realmente uma estrutura familiar neste momento para realizar o transplante, considerando que isto implicaria em estar levando para o bloco cirúrgico o pai, a mãee o menino, sendo que outro irmão está internado na UTI. Segundo a psicóloga, a mãe não tem claro a possibilidade de perder o filho no transplante. ... Vários médicos manifestaram-se contrários ao exposto pela Psicologia, alegando terem conversado com a mãe e avaliado que a família está preparada. (Registro de observação em reunião de equipe multidisciplinar de transplante).

- A importância do emocional:

Os psicólogos ainda trazem muito assim, ah tudo emocional, tudo tem um fundo emocional, e tudo não sei o quê. Eclaro que eu também acredito nisso, acho que como causa ou conseqüência, a questão emocional tá sempre implicada. Mas sempre achei que as pessoas eram muito reducionistas assim. O médico acha que tudo é do corpo, e tudo é o corpo que produz (D1).

A minh a frustração assim em relação a essa trajetória é que demora bastante tempo, a gente tem um quadro clínico de médicos credenciados em torno de três mil e seiscentos, quatro mil médicos né. A gente tem o que, nós não temos 10\% dessa população que solicita atendimento sempre quando o paciente está depressivo, né. É só quando eles não estão conseguindo manejar uma situação, que o paciente está ali deixando eles de cabelo em pé, bom então passa pro psicólogo que ele tem, ele tem condições de dar conta disso né, idealizando a figura do psicólogo como se fosse uma pessoa milagrosa, que vaiconseguir botar tudo no lugar (A1).

- Conhecimento do trabalho do psicólogo:

Basicamenteéfazero contato com esse médico e explicar, o que tuestás fazendo por ele. Te posicionar, dizer olha eu acredito queéisso, isso, eisso. Epra isso tu tem queestudar muito, tu tem que poder discutir com o médico, tem que poder entender o que ele está dizendo. ... tem que saber qualéessalinguagem, prapoder trocarcom esse médico eeleentenderoquêquetutáfalando. Entãoé, eu entendo que é buscar por aí, né. Buscar a capacitação e poder mostrar pra esse médico, porque épra ele que tu tem que mostrar, porque se tu não mostra, ele vaibarrar (A1).

- Análise indutiva: As psicólogas consideram que para se inserir no hospital e conseguir desenvolver seu trabalho é preciso ser persistente na defesa de suas idéias e buscar interagir com os demais profissionais. É preciso 94 indicar quais benefícios podem ser obtidos com a intervenção psicológica para que o serviço passe a ser solicitado. Com esses cuidados, o trabalho tende a ser aceito e valorizado por parte daqueles profissionais que reconhecem a interferência de aspectos emocionais no quadro clínico de seus pacientes.

Os reducionismos profissionais e as diferenças hierárquicas são identificados como fatores que impedem o desenvolvimento da prática multidisciplinar. O reducionismo está tanto do lado da Psicologia, exacerbando-se a defesa do emocional, quanto do lado da medicina, limitando-se ao tratamento do corpo. Nesses impasses, uma saída tem sido a promoção de amplas discussões sobre as relações mente-corpo. No entanto, para que esse tipo de discussão avance e traga benefícios práticos, é preciso que as psicólogas reconheçam as implicações orgânicas no estado emocional dos pacientes, e os médicos acatem a relevância do psiquismo na recuperação dos pacientes.

As psicólogas reconhecem as dificuldades que sentem para expor e sustentar seus posicionamentos perante os médicos. Há realmente um desafio à capacitação. Um psicólogo para manter um diálogo produtivo com o médico precisa dispor de uma visão ampla da sua ciência e da linguagem do médico. No entanto, a falta de consenso sobre o papel da ciência na formação em Psicologia parece dificultar o desenvolvimento de habilidades profissionais para a atualização científica.

\section{Descrição do segundo tema: prática multi- disciplinar na perspectiva da Psicologia}

Como se constitui a rotina e a realidade vivida na prática multidisciplinar? As falas escolhidas são apresentadas nos excertos que seguem:

Se eu estou atendendo, eu participo do round quando eu tenho assim, alguma paciente que eu preciso falar alguma coisa com alguém da equipe, que a gente precisa trocar. Enaverdade, o chefe da equipe gostaria da minha presença na equipe todos os dias. Só que assim, são 24 leitos e eu não consigo dar cobertura pra todos. Então se eu fico ali no round, é demorado, é muito tempo queeu perco, eu não perco né, mas assim, eles estão discutindo questões médicas né. Então eu participo quando eu vou poder dar alguma assessoria do ponto de vista assim, ah como é que vai conduzir aquele caso (C2).

Tem grupos que a gente compartilha e olheláné. Eu sinto isso é nos andares né, na internação de clínica, cirurgia, 
porque os médicos eles são, eles estão muito mais preocupados com a questão do paciente estar bem, se a ferida operatória tá bem, se tá curada. Difícil eles verem um paciente como um todo assim, uma pessoa que precisa de ajuda, que se estiver deprimida não vai melhorar e a ferida não vaifechar (B1).

Euposso dizer que a equipe que o trabalho multidisciplinar mais acontece é com a psiquiatria. Tem toda uma proposta deles também de trabalhar assim, de poderem se dar conta que muitas vezes fica tudo centralizado no médico, mas que não deve ficar. Até tem um processo que é de gerenciamento de pacientes, então eu sou responsável por alguns pacientes, a assistente social por outros, e todo mundo fica mais ou menos no mesmo nível assim de responsabilidade. Não é só o médico que tem que arcar com tudo, vai ter alta, não vai ter alta, vai fazer isso, fazer aquilo (B1).

O trabalho multidisciplinar aqui não acontece, aqui dentro, aqui não acontece. De longe isso que é pra ser, que a gente entende, não acontece. O que a gente tenta é trocar assim com um ou outro profissional (A2).

Não temos muito tempo para estarnessas reuniões assim. Mas tem acontecido, tem um desejo deles em que a gente esteja inserida ali, bem marcada (A2).

- Análise indutiva: é notório nas falas que apesar do elogio ao multidisciplinar, tal prática paira no ideário futuro da prática hospitalar. No caso da Psicologia aparecem dois limitadores. Um deles é o reduzido número de psicólogos e, por conseguinte, a limitação de tempo, refletida nas dificuldades em conciliar o acompanhamento às visitas médicas, a discussão de casos, e o atendimento psicológico. O outro limitador é a disposição dos chefes de serviços em conceder espaço ao trabalho da equipe. A adesão de mais médicos ao trabalho em equipe é certamente uma questão de tempo, tendo em vista a necessidade de o profissional desenvolver uma visão sistêmica e integrada do ser humano e do processo saúde/doença. Enquanto isso, espera-se que os psicólogos se disponham a compartilhar seus conhecimentos com os demais profissionais.

\section{Segunda parte: a inserção da Psicologia no trabalho multidisciplinar na percepção da Enfermagem}

Como realizado na secção anterior, a descrição será composta com excertos procedentes das entrevistas com as enfermeiras. O foco é o reconhecimento, por parte da Enfermagem, das contribuições da Psicologia para o desenvolvimento do trabalho multidisciplinar e o tratamento dos pacientes. A narrativa desdobra-se em três temas:

\section{1) Descrição do primeiro tema: reconhe- cendo a Psicologia}

Qual a percepção da Enfermagem sobre o trabalho realizado pela Psicologia?

Foina maternidade [que] eu pude acompanhar bem de perto essa situação, juntamente com a Psicologia. A gente fica entendendo [como se dá] a troca entre profissionais ... do psicólogo com a enfermeira. A gente começa a entender um pouco melhor do paciente, também, e pode ajudar até na questão do cuidado (A3).

Eu comecei a perceber que aquelas mães e aqueles casais que eram acompanhados pela psicóloga, não que eles não sentissem, eles sentiam todo o processo que os outros sentiam, só que de uma forma mais, ãh, não tão ansiosa, sabe, o processo ele era mais lento talvez, não, não émais lento que eu quero dizer, era mais brando, né. Ele não era uma coisa que vinha assim de qualquer jeito. Etambém aliviava pra Enfermagem, bem como se dizassim, aliviava pra Enfermagem por que as angústias, os anseios, a ansiedade daqueles pais elas eram minimizadas (A3).

Nós profissionais sentimos necessidade também do psicólogo nos ajudando em alguns momentos, tipo, numa situação de extrema gravidade do paciente, numa situação de morte. A gente sente muita falta também, pra equipe também. Algumas decisões que tem que serem tomadas. Eu acho que o psicólogo seria muito bom se ele pudesse trabalhar com essa equipe...e ajudando na situação, tipo não tem mais nada pra fazer com esse paciente e aí. Como é que vai ser tratado isso com os pais, como éque vaiser tratado com os médicos, com a equipe de Enfermagem. Então acho que um profissional que tá fazendo falta, tanto pro paciente quanto pra equipe (B3).

- Análise indutiva: os profissionais da Enfermagem consideram que as atribuições da Psicologia consistem no atendimento a pacientes e familiares que enfrentam situações de crise, risco de vida e de morte, isto é, em trabalhar a aceitação da doença e a adesão ao tratamento com pacientes crônicos; preparar crianças para cirurgia; trabalhar alta hospitalar com crianças que apresentam hospitalismo; trabalhar implicações familiares e risco de morte com pacientes candidatos a transplante; preparar gestantes de alto risco para o 
pós-operatório e possível internação de seu filho na UTI neonatal; trabalhar fantasias e sentimentos de culpa de pais que têm filhos com anomalia; oferecer apoio aos familiares na comunicação de más notícias, tais como risco de vida e ausência de tratamento; e facilitar o processo de luto dos familiares que enfrentam situações de óbito.

A Enfermagem também tem expectativas claras com relação à contribuição da Psicologia às equipes. Espera-se que a Psicologia assessore na definição de condutas e tratamentos, trazendo conhecimentos sobre a influência dos aspectos emocionais no quadro clínico dos pacientes. Desse modo, é atribuída ao psicólogo a função de qualificar a equipe para ser capaz de tomar decisões condizentes com as necessidades dos pacientes. Isso implica tornar a equipe mais autônoma, já que nem sempre o profissional da Psicologia tem disponibilidade para atendê-la. É interessante notar que na última fala foi introduzido o trabalho em equipe que será tema da próxima descrição.

\section{2) Descrição do segundo tema: a equipe multidisciplinar na perspectiva da Enfermagem}

Como a Enfermagem percebe e vivencia a multidisciplinaridade?

Logo que a gente se forma, isso não é muito claro dentro da tua cabeça, né, porque tu queres trabalhar, tu queres fazer técnica. Mas tu vais amadurecendo e tu vais percebendo cada vez mais a importância da atuação da equipe interdisciplinar, e o quanto isso é importante prapoderfazer o cuidado (A3).

Participei de um grupo de maus tratos, onde eram vários profissionais, era médico, era psicólogo, serviço social, e a enfermagem que fazia o trabalho. E aí conheci como funcionava cada profissional. Eaíque eu fiquei viciada, eu não sei mais trabalhar sem estar em grupo, não sei, não sei mesmo, eu sinto falta quando eu não posso contar com alguém. Porque eu consegui me dar conta que o meu serviço tem sempre um momento que ele tem limite. Ele chega a um ponto que não está mais em mim em resolver, porfalta de conhecimento na área e outra talvez por habilidade profissional, que depende de outro profissional(D3).

Normalmente quem faz e acontece [trabalho em 96 equipe] são os médicos mais simpáticos, mais agradáveis praatender, porque eles mesmos se propõem a isso. Tem uns que não participam, não adianta, mas normalmente vem algum. Vem algum médico, mesmo que ele venha contrariado, mas a gente mostra a importância. Esse éo profissional que a gente tem mais dificuldade pra trazer praequipe(D3).

- Análise indutiva: As enfermeiras reconhecem as contribuições da equipe multidisciplinar e distinguem, com clareza, as vantagens para a análise do caso clínico quando ocorrem interações entre profissionais das desvantagens decorrentes do distanciamento do trabalho da equipe. Aquelas que vivenciaram ambas as situações dizem valorizar ainda mais a possibilidade de poder contar com o apoio de colegas com outra formação.

\section{3) Descrição do terceiro tema: demanda por Psicologia}

Como a Enfermagem vê a participação da Psicologia nas equipes multidisciplinares?

Que pudesse ter um momento que a Psicologia pudesse trazer isso pra equipe, que não fosse só pro enfermeiro, mas pra equipe em si, assim o médico juntamente né, que a gente pudesse entender um pouquinho mais né. Por mais que a enfermeira possa fazer esse link, né, mas que pudesse também a Psicologia participar de uma reunião juntamente com a Enfermagem, médicos (A3).

No início assim, como era menos áreas acho que o psicólogo teria que atender, até a presença dele era mais freqüente aqui. Hoje em dia é mais aluno, com a supervisão da Psicologia, da psicóloga, mas aqui conosco quem trabalha maiséo aluno. Eisso a gente sente muita falta. Por que o aluno na verdade ele tá aprendendo. Teria que na verdade o psicólogo que tá, o orientador dele estar mais presente, e a gente sente muito (B3).

As acadêmicas de Enfermagem comentaram sobre a importância de escolher um lugar calmo para amamentar a criança, por ser este um momento de intimidade entre a mãe e o bebê, em que um conhece o outro. A estagiária de Psicologia não comentou nada. (Registro de observação de atendimento multidisciplinar de um grupo de gestantes).

- Análise indutiva:foram mencionados dois tipos de demandas psicológicas. A primeira requer maior presença do psicólogo na equipe, explicitando suas posições e intervenções para todo o grupo e não 
somente para enfermeiras por ocasião de visitas a pacientes. A segunda traz um aspecto positivo, o reconhecimento da demanda, e um aspecto preocupante, a inserção prematura de estagiários no serviço. As enfermeiras reconheceram a limitação de tempo da Psicologia para atender toda a demanda existente. No entanto consideram que as intervenções psicológicas seriam mais eficazes se esses profissionais atendessem a um menor número de unidades e investissem mais nas situações cuja atuação está consolidada.

\section{Discussão}

Conforme indicado anteriormente (LoBianco et al., 1994; Romano, 1999), o trabalho da Psicologia vai se consolidando na prática hospitalar. Tal impressão é corroborada pelas psicólogas entrevistadas nesta pesquisa. Para elas, a efetividade do trabalho depende da conduta na equipe multidisciplinar e da capacidade de mostrar os resultados obtidos. O trabalho da Psicologia é mais bem compreendido em instituições com predomínio do modelo biopsicossocial.

No entanto não se pode desprezar a tradição histórica do modelo biomédico e nem assumi-lo como obstáculo ao trabalho. Por sua vez, os avanços da prática psicológica estão associados à qualificação do psicólogo, mais especificamente à capacidade de justificar procedimentos e ações (Wild et al., 2003). Nesse sentido, espera-se que os psicólogos sejam críticos o suficiente para avaliar quando é pertinente aceitar a argumentação dos demais profissionais e quando realçar a especificidade de sua atuação. $O$ trabalho em grupo requer objetividade, clareza e evidências empíricas. Nesse sentido, Gorayeb e Guerelhas (2003) apresentaram um belo estudo sobre como registrar e analisar as intervenções psicológicas em hospitais. Do mesmo modo, Sheridan (1999) relatou que há evidências empíricas confiáveis indicando que a Psicologia contribui tanto para a qualificação do atendimento quanto para a redução de custos em hospitais.

O aparente consenso da Psicologia sobre suas funções e da Enfermagem sobre as atribuições do psicólogo confirmam que o trabalho em equipe é fundamental para o reconhecimento das diferentes áreas de atuação. $\mathrm{O}$ relato das enfermeiras reitera a percepção das psicólogas de que a valorização dos serviços depende dos resultados obtidos. De relance, tal interpretação pode parecer óbvia. Contudo o reconhecimento pela Psicologia da necessidade de mostrar resultados é recente. Durante muito tempo, acreditou-se que a satisfação com as intervenções psicológicas era medida pela subjetividade de cada um. Entretanto a prática psicológica em hospitais precisa ser ampliada, o que requer maior presença em diferentes equipes, mesmo naquelas não muito receptivas. Por exemplo, Hallas (2004) reconhece, em um texto didático e informativo sobre as aplicações psicológicas no cuidado à saúde na Inglaterra, que o trabalho multidisciplinar, apesar de intenso e efetivo, ocorre principalmente em nível informal.

\section{Considerações Finais}

Os serviços de saúde contam hoje com um conjunto diversificado de profissionais em condições de oferecer atendimentos de altíssima qualidade. A articulação desses atendimentos em equipes multidisciplinares sistematiza o trabalho, melhora os resultados e reduz os custos. As falas deste estudo mostram que tal diversificação pode em um primeiro momento trazer confusão, dificuldade de comunicação, e até frustração. Nesse momento, as entrevistadas enfatizam que a clareza que cada profissional tem de suas funções e a habilidade para comunicar-se com os colegas são fatores preponderantes para a apropriação gradativa e segura da ação multidisciplinar. O interesse pelo trabalho psicológico em hospitais vem crescendo e a Psicologia, como ciência, está preparada para contribuir de modo eficiente e seguro. A ação multidisciplinar, apesar dos desafios, apresenta-se como uma forma promissora e irreversível de atendimento na área da saúde.

\section{Referências}

Bucher, J. S. N. F. (2003). Psicologia da saúde no contexto da saúde pública: uma complexidade crescente. In O. H. Yamamoto \& V. V. Gouveia (Orgs.), Construindo a psicologia brasileira: desafios da ciência e prática psicológica (pp.213-239). São Paulo: Casa do Psicólogo.

Chiattone, H. B. C. (2000). A significação da psicologia no contexto hospitalar. In V. A. Angerami (Org.), Psicologia da saúde: um novo significado para a prática clínica (pp.73-158). São Paulo: Pioneira. 
Crepaldi, M. A. (1999). Bioética e interdisciplinaridade: direitos de pacientes e acompanhantes na hospitalização. Paidéia, 9 (16), 89-94.

Gavião, A. C. D., \& Pinto, K. O. (2000). Representação da interdisciplinaridade: um estudo através do procedimento do desenho-história tema. Revista Brasileira Psiccologia Hospitalar, 3 (1), 3-12.

Gomes, W. B. (1998). A entrevista fenomenológica e o estudo da experiência consciente. In W. B. Gomes (Org.), Fenomenologia e pesquisa em psicologia (pp.19-44). Porto Alegre: Editora da Universidade/UFRGS.

Gorayeb, R., \& Guerelhas, F. (2003). Sistematização da prática hospitalar em ambientes médicos. Revista Brasileira Terapia Comportamental, 5 (1), 11-19.

Hallas, C. N. (2004). Professional health psychology applied within healthcare services. In S. Michie \& C. Abraham (Orgs.), Health psychology in practice (pp. 353-371). London: Blackwells University Press.

Lanigan, R. L. (1988). Phenomenology of communication. Pittsburgh, PA: Duquesne University Press.

LoBianco, A. C., Bastos, A. V. B., Nunes, M. L. T., \& Silva, R. C. (1994). Concepções e atividades emergentes na psicologia clínica: implicações para a formação. In Conselho Federal de Psicologia (Org.), Psicólogo brasileiro: práticas emergentes e desafios para a formação (pp.7-79). São Paulo: Casa do Psicólogo.

Maclean, L. M., Plotnikoff, R. C., \& Moyer, A. (2000). Transdisciplinary work with psychology from a population helath perspective: an illustration. Journal of Health Psychology, 5 (2), 173-181.

Moré, C. L. O., Crepaldi, M. A., Queiroz, A. H., Wendt, N. C., \& Cardoso, V. S. (2004). As representações sociais do psicólogo entre os residentes do programa de saúde da família e a importância da interdisciplinaridade. Psicologia Hospitalar, 1 (1), 59-75.
Oliveira, V. Z., \& Gomes, W. B. (2004). Comunicação médico-paciente e adesão ao tratamento em adolescentes portadores de doenças orgânicas crônicas. Estudos de Psicologia (Natal), 9 (3), 459-470.

Organização Pan-Americana de Saúde (1996). Promoción de la salud: una antologia (Publicación Científica, 557). Washington, DC: OPAS.

Romano, B. W. (1999). Princípios para a prática da psicologia clínica em hospitais. São Paulo: Casa do Psicólogo.

Remor, E. A. (1999). Psicologia e saúde: apresentação, origens e perspectivas. Psico, 30 (1), 205-217.

Seidl, E. M. F., \& Costa, A. L. Jr. (1999). O psicólogo na rede pública de saúde do Distrito Federal. Psicologia: Teoria e Pesquisa, 15 (1), 27-35.

Sheridian, E.P. (1999). Psychology's future in Medical School's and academic health care centers. American Psychologist, 54 (4), 267-271

Souza, M. L., Gomes, W. B., \& McCarthy, S. (2005). Reversible relationship between quantitative and qualitative data in self-consciousness research: a normative semiotic model for the phenomenological dialogue between data and capta. Quality and Quantity, 39, 199-215.

Wild, M. R., Bowden, K., \& Bell, N. (2003). The provision of clinical psychology services within a general hospital: an analysis and interpretation of referral rates. Scott Medical Journal, 48 (3), 76-81.

Yamamoto, O. H., \& Cunha, I. M. F. F. O. (1998). O Psicólogo em hospitais de Natal: uma caracterização preliminar. Psicologia: Reflexão e Crítica, 11 (2), 345-362.

Recebido em: 31/1/2006

Versão final reapresentada em: 2/5/2006

Aprovado em: 28/8/2006 